\title{
Investigation of High Frequency Properties of Y-type Hexaferrite Dependence on Synthesis Condition
}

\author{
Jung Tae Lim and Chul Sung Kim* \\ Department of Physics, Kookmin University, Seoul 136-702, Korea
}

(Received 21 February 2014, Received in final form 26 March 2014, Accepted 28 March 2014)

\begin{abstract}
The samples of $\mathrm{Ba}_{2} \mathrm{CoZnFe}_{12} \mathrm{O}_{22}$ was synthesized by the solid-state reaction method. The toroids of $\mathrm{Ba}_{2} \mathrm{CoZnFe}_{12} \mathrm{O}_{22}$ were sintered with various sintering temperature at $1050,1100,1150$, and $1200{ }^{\circ} \mathrm{C}$, and studied by x-ray diffractometer, vibrating sample magnetometer, network analyzer, and Mssbauer spectrometer. From the XRD patterns, the density of samples increased with increasing sintering temperature. From the magnetic hysteresis curves up to $10 \mathrm{kOe}$ at $295 \mathrm{~K}$, the saturation magnetization $\left(M_{s}\right)$ of $\mathrm{Ba}_{2} \mathrm{CoZnFe}_{12} \mathrm{O}_{22}$ samples in various sintered at $1050,1100,1150$, and $1200{ }^{\circ} \mathrm{C}$ were showed around $M_{s}=33.0$ emu/g. However, With increasing sintering temperature, the coercivity $\left(H_{c}\right)$ of samples decrease. Complex permeability and permittivity of samples in various sintering temperatures were measured between $100 \mathrm{MHz}$ to $4 \mathrm{GHz}$. With increasing sintering temperature, the permeability of samples increase.
\end{abstract}

Keywords : Y-type hexaferrite, Mössbauer spectroscopy, permeability, permittivity

\section{소결 조건에 따른 Y-type Hexaferrite의 고주파 특성 \\ 임정태 · 김철성* \\ 국민대학교 물리학과, 서울시 성북구 정릉동 861-1, 136-702}

(2014년 2월 21일 받음, 2014년 3월 26일 최종수정본 받음, 2014년 3월 28일 게재확정)

$\mathrm{Ba}_{2} \mathrm{CoZnFe}_{12} \mathrm{O}_{22}$ 시료를 습식분쇄로 이용한 직접 합성법을 사용하였으며, 소결 조건의 변화에 따른 시료 제조후, $\mathrm{x}$-선 회절기 (XRD), 진동시료형 자화율측정기(VSM), 회로망 분석기, 그리고 뫼스바우어 분광기 측정을 이용하여 결정학적 및 자기적 특성을 연구하였다. X-선 회절 실험을 통해 Y-type hexaferrite가 주상임을 알 수 있었고, 소결 온도가 증가할수록 밀도가 증가하였다. 상 온에서 $10 \mathrm{kOe}$ 까지의 자화이력곡선 측정 결과, 포화 자화 값는 모든 시료가 약 $33 \mathrm{emu} / \mathrm{g}$ 으로 비슷한 값이 나왔으며, 보자력은 소 결 온도가 증가할수록 감소하였다. 회로망 분석기를 통해 $100 \mathrm{MHz}$ 부터 $4 \mathrm{GHz}$ 까지 투자율과 유전율을 측정하였다. 그 결과, 소 결 온도가 증가할수록 투자율과 $\tan \delta_{\mu}$ 는 감소하였다.

주제어 : Y-type hexaferrite, 뫼스바우어 연구, 투자율, 유전율

\section{I. 서 론}

현재 무선통신기기의 발달로 고주파 대역에서 Radio frequency(RF) 소재의 소형화, 광대역화, 고효율을 요구되어 있으며, 이로 인해 투자율 $(\mu)$ 과 유전율 $(\varepsilon)$ 의 특성을 가지는 자 성물질을 이용한 RF 소재가 많이 연구되고 있다. 특히, 1950 년대부터 연구가 진행된 Y-type hexaferrite는 자기전기 (magnetoelectric) 효과에 의한 실온에서의 발현 가능성이 있

(C) The Korean Magnetics Society. All rights reserved.

*Corresponding author: Tel: +82-2-910-4752,

Fax: +82-2-910-5170, e-mail: cskim@kookmin.ac.kr
는 다중강체라는 흥미로운 물리적 특성을 가지고 있으며, 또 한, 높은 자기 이방성에 의해 $100 \mathrm{MHz}$ 부터 수 $\mathrm{GHz}$ 까지의 고주파 대역에서의 RF소재로써 연구되어지고 있다[1-6]. 고주 파에서의 주파수 특성에 영향을 끼치는 투자율은 전이금속의 분포와 소결 조건에 직접적으로 관련되어 있다. Y-type hexaferrite의 모조성인 $\mathrm{Ba}_{2} \mathrm{Co}_{2} \mathrm{Fe}_{12} \mathrm{O}_{22}\left(\mathrm{Co}_{2} \mathrm{Y}\right)$ 에 경우 낮은 포 화자화 $\left(M_{\mathrm{s}}\right)$ 값에 의해 투자율이 상대적으로 낮게 보고되고 있 다[7]. 따라서, 본 연구에서는 $\mu$ 에 영향을 미치는 $M_{\mathrm{s}}$ 를 향상 시키기 위해 비자성 $\mathrm{Zn}$ 이온을 치환함으로써 증가시키고, $1050,1100,1150,1200^{\circ} \mathrm{C}$ 에 해당하는 각각의 소결온도에서 시료를 제조 후, $\mathrm{x}$-선 회절기(XRD)와 진동시료형 자화율측정 
기(VSM)을 이용하여 결정구조 및 자기적 특성에 대해 연구 하였고, 고주파에서의 전자기적 특성을 회로망 분석기(NA)로 통해 확인하였다. 또한, 뫼스바우어 분광기를 통해 Y-type hexaferrite 구조안에서 자성 이온의 부격자 점유율과 미시적 인 자기적 기원에 대해서 연구하였다.

\section{II. 실험방법}

$\mathrm{Ba}_{2} \mathrm{CoZnFe}_{12} \mathrm{O}_{22}$ 시료를 직접 합성법을 사용하여 제조하였 다. $\mathrm{BaCO}_{3}(98 \%), \mathrm{Co}_{3} \mathrm{O}_{4}(99 \%), \mathrm{ZnO}(99.8 \%), \mathrm{Fe}_{2} \mathrm{O}_{3}(99.42 \%)$ 를 출발 물질로 사용하여, ball Mill를 통해 24시간 동안 습 식분쇄를 하였다. 분쇄 된 시료를 건조하여 $1000{ }^{\circ} \mathrm{C}$ 에서 3 시 간 동안 하소를 한 후, 하소 된 시료를 다시 ball Mill로 통 해 12 시간 동안 습식분쇄를 하였다. 마지막으로 분쇄 된 시료 를 건조하여, 내경이 $3.04 \mathrm{~mm}$, 외경이 $7 \mathrm{~mm}$ 인 toroid 형태로 성형 후 $1050,1100,1150,1200{ }^{\circ} \mathrm{C}$ 온도에서 각각 소결하였 다. 제조된 시료의 결정학적 특성은 $\mathrm{Cu}-\mathrm{K} \alpha$ 선 $(\lambda=1.5406 \AA)$ 을 사용하는 Philips 사의 X'pert PW1830 XRD를 이용하여 $\mathrm{XRD}$ 실험을 통하여 확인하였으며, 거시적인 자기적 특성은 $\mathrm{VSM}$ 으로 확인하였다. 또한, 뫼스바우어 분광 실험을 통해 미 시적인 자기적 특성을 분석 하였다. 전기역학적 등가속도형 뫼스바우어 분광기를 이용하였으며, $\gamma$-선원은 $\mathrm{Rh}$ 금속에 확산 시킨 실온상태의 $50 \mathrm{mCi}$ 의 ${ }^{57} \mathrm{Co}$ 단일선원을 사용하였다. 시료 의 주파수에 따른 $\mu$ 와 $\varepsilon$ 의 특성은 $100 \mathrm{kHz}$ 에서 $8.5 \mathrm{GHz}$ 까지 측정이 가능한 Agilent 사의 $\mathrm{E} 5071 \mathrm{C} \mathrm{NA}$ 를 이용하여 toroid 형태의 소결체로 측정하여 Agilent 85071 프로그램을 통하여 Nicolson-Ross model로 계산하여 $\mu$ 와 $\varepsilon$ 를 분석하였다[8].

\section{III. 결과 및 논의}

$1050,1100,1150,1200{ }^{\circ} \mathrm{C}$ 의 소결온도에서 제조된 $\mathrm{Ba}_{2} \mathrm{CoZnFe}_{12} \mathrm{O}_{22}$ 시료에 대한 $295 \mathrm{~K}$ 에서의 $\mathrm{XRD}$ 결과를 Fig. 1에 나타내었다. XRD 측정 결과, 모든 시료는 Y-type상 이 주상임을 확인 할 수 있었으며, 시료의 결정구조는 공간 그룹이 $R-3 m$ 인 rhombohedral구조로 확인되었다 $[9,10]$. 소결 온도가 증가하면서, 단위포의 부피가 증가하였으며, toroidal 형태의 실제 측정 밀도도 $3.9,4.4,4.5,4.8 \mathrm{~g} / \mathrm{cm}^{3}$ 로 증가하 였다. 이러한 밀도의 증가는 소결 온도의 증가에 따른 grain size의 증가로 판단되며, 공극이 없는 이론적인 Y-type hexaferrite의 밀도에 가까운 $1200{ }^{\circ} \mathrm{C}$ 에서 소결한 시료가 높은 투자율을 보일 것으로 예상된다.

Fig. 2 는 $295 \mathrm{~K}$ 에서 $10 \mathrm{kOe}$ 까지의 측정 된 자기이력곡선을 보여준다. 자기이력곡선에서 각각의 소결온도에서 제조된 $\mathrm{Ba}_{2} \mathrm{CoZnFe}_{12} \mathrm{O}_{22}$ 시료는 페리자성의 거동을 보였으며, 포화자

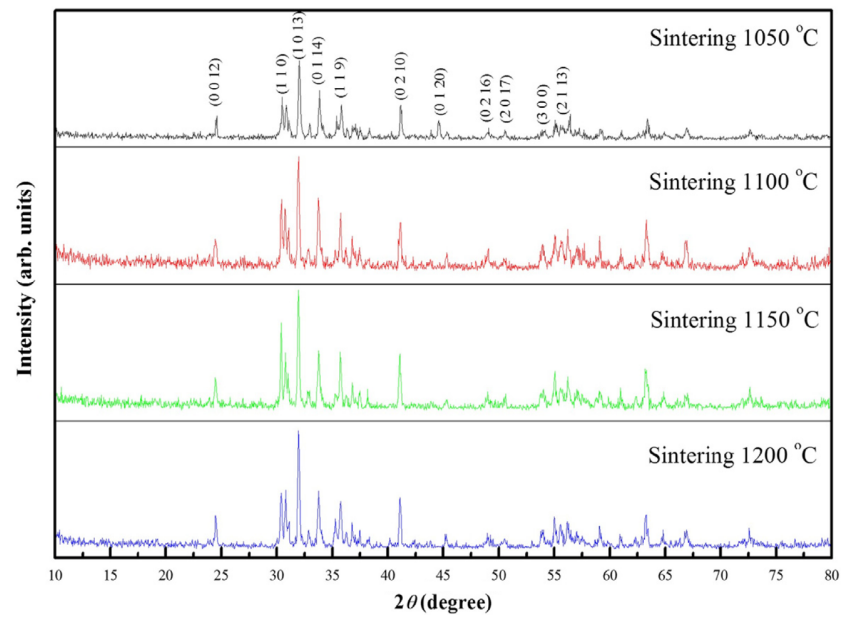

Fig. 1. (Color online) Refined $\mathrm{x}$-ray diffraction patterns for $\mathrm{Ba}_{2} \mathrm{CoZnFe}_{12} \mathrm{O}_{22}$ at $295 \mathrm{~K}$.

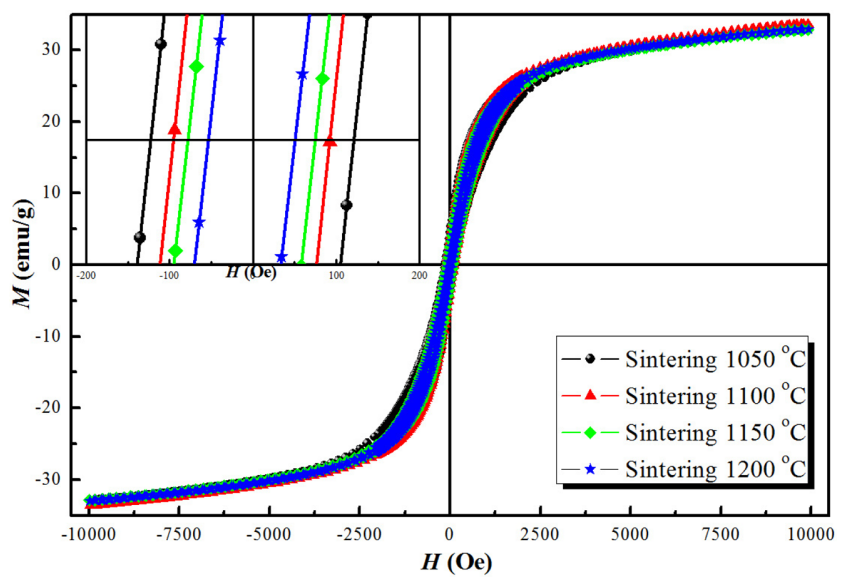

Fig. 2. (Color online) The hysteresis loops of $\mathrm{Ba}_{2} \mathrm{CoZnFe}_{12} \mathrm{O}_{22}$ at $295 \mathrm{~K}$.

화 값 $\left(M_{\mathrm{s}}\right)$ 은 각각 $33.0,33.6,32.9,33.0 \mathrm{emu} / \mathrm{g}$ 으로 비슷한 결과를 나타내었다. 비자성 $\mathrm{Zn}$ 이온이 down-spin 방향의 tetrahedral site로 치환되어, 모조성 $\mathrm{Co}_{2} \mathrm{Y}$ 보다 포화자화 값이 증가하여, 투자율이 증가 될 것으로 예상된다[9]. 또한, 보자 력 $\left(H_{c}\right)$ 은 소결온도가 증가할수록 각각 $121.7,93.8,76.6$, $51.9 \mathrm{Oe}$ 로 감소하였다. 이는 소결체의 grain size의 증가에 의 한 것으로 판단된다.

Fig. 3 는 주파수에 대한 각각의 온도에서 소결된 시료들의 $\mu$, 투자 손실 $\left(\tan \delta_{\mu}\right), \varepsilon$, 유전 손실 $\left.\tan \delta_{\varepsilon}\right)$ 특성을 각각 나 타내었고, 목표 주파수인 $1 \mathrm{GHz}$ 의 특성 결과를 Table I에 나 타내었다. 소결온도가 증가함에 따라서 $\mu$ 는 증가를 하였다. 이는 비슷한 $M_{\mathrm{s}}$ 값에도 불구하고, 소결온도가 증가하여 grain size의 증가에 의한 것으로 판단된다. 일반적인 금속 이온을 치환한 결과와 마찬가지로, $\mu$ 와 $\tan \delta_{\mu}$ 가 소결온도가 증가함 에 따라 동시에 증가 하였다. 따라서, $1 \mathrm{GHz}$ 에서 $\tan \delta_{\mu}$ 이 

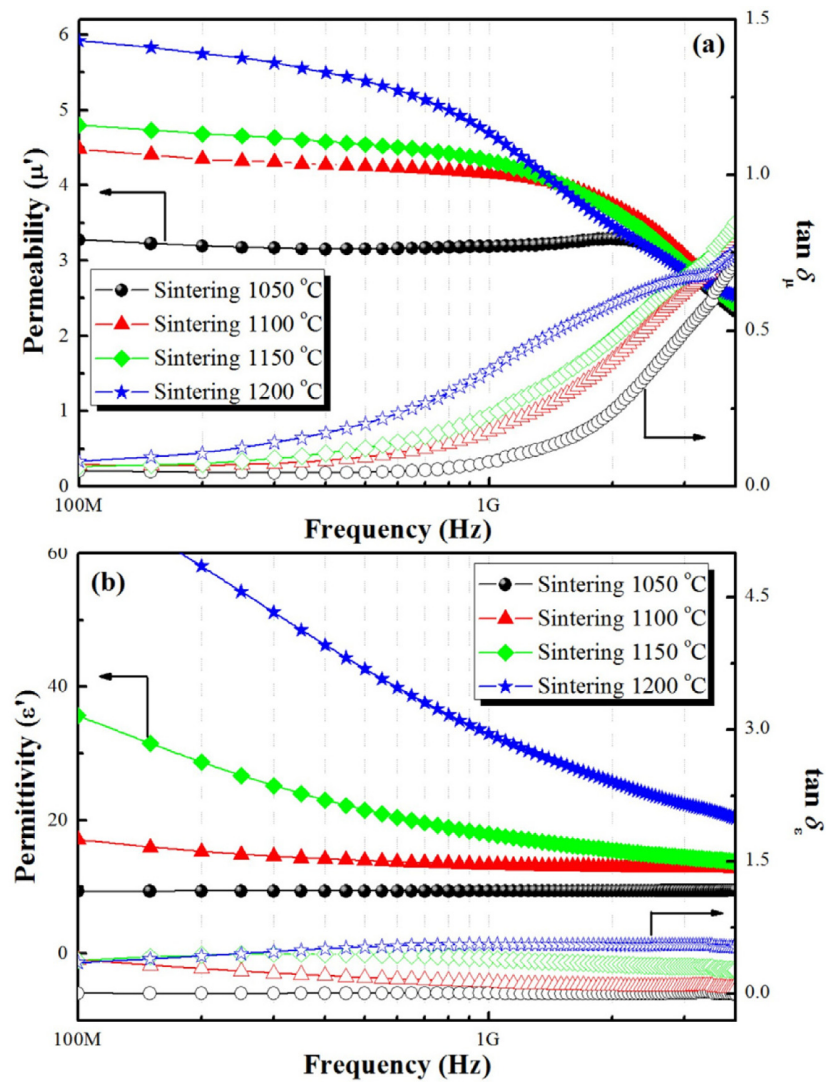

Fig. 3. (Color online) Frequency dependence of properties for $\mathrm{Ba}_{2} \mathrm{CoZnFe}_{12} \mathrm{O}_{22}$ at various temperature.

Table I. Frequency dependence of permeability $\mu$, magnetic loss tan $\delta_{\mu}$, permittivity $\varepsilon$, dielectric loss tan $\delta_{\varepsilon}$ for $\mathrm{Ba}_{2} \mathrm{CoZnFe}_{12} \mathrm{O}_{22}$ samples at various sintering temperature.

\begin{tabular}{ccccc}
\hline \hline Sintering Temp. & $\mu$ & $\tan \delta_{\mu}$ & $\varepsilon$ & $\tan \delta_{\varepsilon}$ \\
\hline $1050{ }^{\circ} \mathrm{C}$ & 3.186 & 0.078 & 9.384 & 0.009 \\
$1100{ }^{\circ} \mathrm{C}$ & 4.169 & 0.176 & 13.332 & 0.132 \\
$1150{ }^{\circ} \mathrm{C}$ & 4.322 & 0.230 & 17.920 & 0.402 \\
$1200^{\circ} \mathrm{C}$ & 4.693 & 0.371 & 32.954 & 0.564 \\
\hline
\end{tabular}

0.1 이하의 값을 가지는 $1050{ }^{\circ} \mathrm{C}$ 에서 소결한 $\mathrm{Ba}_{2} \mathrm{CoZnFe}_{12} \mathrm{O}_{22}$ 시료가 $\mathrm{GHz}$ 영역에서의 자성체 $\mathrm{RF}$ 소재로서의 응용가능성 이 있음을 확인하였다. 또한, $\varepsilon$ 의 경우 $1150{ }^{\circ} \mathrm{C}$ 이상에서 소 결한 시료는, 모든 주파수영역에서 일정하게 유지하지 못하고, 소결온도가 증가함에 따라, $\varepsilon$ 와 $\tan \delta$ 가 모두 증가하였다.

$1 \mathrm{GHz}$ 에서 가장 좋은 특성을 가진 $1050{ }^{\circ} \mathrm{C}$ 으로 소결한 $\mathrm{Ba}_{2} \mathrm{CoZnFe}_{12} \mathrm{O}_{22}$ 시료의 미시적인 자기적 거동을 확인하기 위 해 뫼스바우어 분광실험을 수행하였다. Fig. 4 는 $1050{ }^{\circ} \mathrm{C}$ 에서 소결한 $\mathrm{Ba}_{2} \mathrm{CoZnFe}_{12} \mathrm{O}_{22}$ 시료의 $4.2 \mathrm{~K}$ 의 뫼스바우어 스펙트럼 을 보여주고 있다. Y-type hexaferrite는 $3 b_{\mathrm{VI}}, 6 c_{\mathrm{IV}}{ }^{*}, 6 c_{\mathrm{VI}}$, $18 h_{\mathrm{VI}}, 6 c_{\mathrm{IV}}, 3 a_{\mathrm{VI}}$ 의 6 개의 결정학적 부격자를 가지고 있으며, 이에 따라 6 개의 sextets으로 최소자승법에 의한 Lorentizan

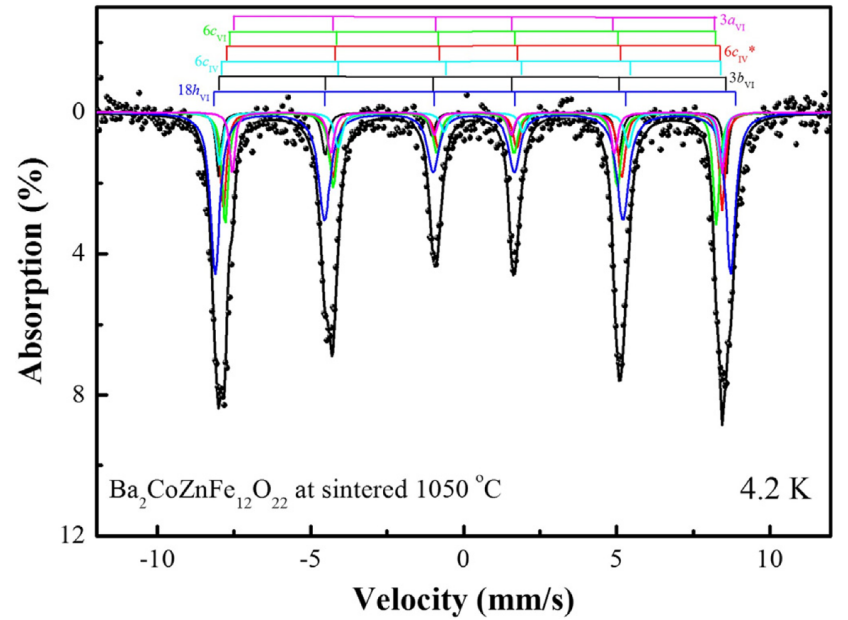

Fig. 4. (Color online) Mössbauer spectra of $\mathrm{Ba}_{2} \mathrm{CoZnFe}_{12} \mathrm{O}_{22}$ at $4.2 \mathrm{~K}$.

Table II. Results of Mössbauer spectra for $\mathrm{Ba}_{2} \mathrm{CoZnFe}_{12} \mathrm{O}_{22}$ in sintered $1050{ }^{\circ} \mathrm{C}$ at $4.2 \mathrm{~K}$.

\begin{tabular}{lrrrrrr}
\hline \hline & \multicolumn{1}{c}{$3 b_{\mathrm{VI}}$} & \multicolumn{1}{c}{$6 c_{\mathrm{IV}}{ }^{*}$} & \multicolumn{1}{c}{$6 c_{\mathrm{VI}}$} & \multicolumn{1}{c}{$18 h_{\mathrm{VI}}$} & \multicolumn{1}{c}{$6 c_{\mathrm{IV}}$} & \multicolumn{1}{c}{$3 a_{\mathrm{VI}}$} \\
\hline$H_{\text {hf }}(\mathrm{kOe})$ & 514.97 & 506.11 & 498.41 & 523.22 & 508.93 & 497.40 \\
$\delta(\mathrm{mm} / \mathrm{s})$ & 0.28 & 0.37 & 0.31 & 0.32 & 0.43 & 0.37 \\
Area $(\%)$ & 8.45 & 15.45 & 18.50 & 40.55 & 8.53 & 8.52 \\
\hline
\end{tabular}

Line으로 분석하였으며, 그 분석치는 Table II에 나타내었다. 분석 결과, 주변에 가장 많은 자성 이온이 분포한 $18 h_{\mathrm{VI}}$ site 의 초미세자기장 $\left(H_{h f}\right)$ 이 가장 큰 것으로 분석되었고, T-block 보다 상대적으로 작은 S-block 안에 있는 $6 c_{\mathrm{IV}}, 3 b_{\mathrm{VI}}$ site의 $H_{h f}$ 이 크게 분석되었다. 이성질체 이동치 $(\delta)$ 값을 통해 시료 의 $\mathrm{Fe}$ 이온은 모두 $\mathrm{Fe}^{3+}$ 상태와 high spin으로 존재함을 알 수 있다. 또한, $3 b_{\mathrm{VI}}, 6 c_{\mathrm{IV}}{ }^{*}, 6 c_{\mathrm{VI}}, 18 h_{\mathrm{VI}}, 6 c_{\mathrm{IV}}, 3 a_{\mathrm{VI}}$ 부격자의 점유율은 각각 $8.45,15.45,18.50,40.55,8.53,8.52 \%$ 이었 으며, 이는 비자성 $\mathrm{Zn}$ 이온이 down-spin 방향의 tetrahedral site에 치환되어, $\mathrm{Ba}_{2} \mathrm{Co}_{2} \mathrm{Fe}_{12} \mathrm{O}_{22}$ hexaferrite보다 투자율이 증 가된 것으로 해석된다.

\section{IV. 결 론}

습식분쇄를 통한 직접 합성법으로 제조된 $\mathrm{Ba}_{2} \mathrm{CoZnFe}_{12} \mathrm{O}_{22}$ 시료를 $\mathrm{XRD}, \mathrm{VSM}, \mathrm{NA}$, 뫼스바우어 분광기 측정을 이용하 여 결정학적 및 자기적 특성을 연구하였다. XRD을 통해 Ytype hexaferrite가 주상임을 알 수 있었고, 소결 온도가 증가 함에 따라 grain size가 증가하였다. $295 \mathrm{~K}$ 에서 $10 \mathrm{kOe}$ 까지의 자화이력곡선 측정 결과, $M_{\mathrm{s}}$ 값는 모든 시료가 약 $33 \mathrm{emu} / \mathrm{g}$ 으로 비슷한 값이 나왔으며, $H_{c}$ 은 소결 온도가 증가할수록 감소하였다. NA를 통해 $100 \mathrm{MHz}$ 부터 $4 \mathrm{GHz}$ 까지 투자율과 
유전율을 측정하였다. 그 결과, 소결 온도가 증가할수록 $\mu$ 과 $\tan \delta_{\mu}$ 는 감소하였다. 이는 $\mu$ 의 증가에 $M_{\mathrm{s}}$ 값보다 grain size가 큰 영향을 끼치는 것으로 판단된다. 또한, $1 \mathrm{GHz}$ 에서 $\tan \delta_{\mu}$ 이 0.1 이하의 값을 가지는 $1050{ }^{\circ} \mathrm{C}$ 에서 소결한 $\mathrm{Ba}_{2} \mathrm{CoZnFe}_{12} \mathrm{O}_{22}$ 시료가 $\mathrm{GHz}$ 영역에서의 자성체 $\mathrm{RF}$ 소재로서의 응용가능성 이 있음을 확인하였다. 또한, 뫼스바우어 분광실험을 통해 비 자성 $\mathrm{Zn}$ 이온이 down-spin 방향의 tetrahedral site에 치환 되는 것을 확인했다.

\section{감사의 글}

본 논문의 연구는 2013년도 정부(교육과학기술부)의 재원 으로 한국연구재단의 기초연구사업 지원을 받아 수행되었습 니다(2013-000671).

\section{References}

[1] B. W. Li, Y. Shen, Z. X. Yue, and C. W. Nan, Appl. Phys. Lett.
89, 132504 (2006)

[2] J. W. Wang, A. L. Geiler, V. G. Harris, and C. Vittoria, J. Appl. Phys. 107, 09A515 (2010).

[3] Y. Bai, J. Zhou, Z. Yue, Z. Gui, and L. Li, J. Appl. Phys. 98, 063901 (2005).

[4] H. J. Kwon, J. Y. Shin, and J. H. Oh, J. Appl. Phys. 75, 6109 (1994).

[5] T. Kimura, G. Lawes, and A. P. Ramirez, Phys. Rev. Lett. 94, 137201 (2005).

[6] J. Lee, Y. K. Hong, S. Bae, J. Jalli, G. S. Abo, J. Park, W. M. Seong, S. H. Park, and W. K. Ahn, J. Appl. Phys. 109, 09E530 (2011).

[7] A. Collomb, J. Muller, and T. Fournier, Mat. Res. Bull. 28, 621 (1993).

[8] Y. Bai, J. Zhou, Z. Gui, Z. Yue, and L. Li, J. Magn. Magn. Mater. 264, 44 (2003).

[9] A. M. Nicolson and G. F. Ross, IEEE Trans. Instrum. Meas. 19, 377 (1970).

[10] J. T. Lim and C. S. Kim, IEEE Trans. Magn. 49, 4192 (2013).

[11] K. L. Cho and C. S. Kim, IEEE Trans. Magn. 49, 4291 (2013). 